D]

'Maastricht University, Faculty of Health, Medicine and Life Sciences, Educational Development and Research, Maastricht, The Netherlands. 2European Respiratory Society, Educational Activities Dept, Lausanne, Switzerland. ${ }^{3}$ University Hospital of North Midlands NHS Trust, Stokeon-Trent, UK. ${ }^{4}$ Hospital del Mar, IMIM, DCEXS, Universitat Pompeu Fabra, CIBERES, ISCIII, Barcelona, Spain. ${ }^{5}$ Dept of Pulmonary Diseases, Catharina Hospital, Eindhoven, The Netherlands. ${ }^{6} \mathrm{Clinic}$ of Respiratory Medicine and Pulmonary Cell Research, University Hospital Basel, Basel, Switzerland. 'Johann Wolfgang Goethe University Hospital, Respiratory Medicine, Frankfurt am Main, Germany.

Cite as: Sehlbach C, Farr A, Allen $\mathrm{M}$, et al. ERS Congress highlight: educational forum on continuing professional development. Breathe 2018; 14: e12-e16.

\title{
ERS Congress highlight: educational forum on continuing professional development
}

Each year as part of its International Congress, the European Respiratory Society (ERS) dedicates a session to discuss the key themes in medical education affecting respiratory professionals working not only throughout Europe but worldwide. The forum is open to national societies, public health officials and patient representatives, as well as individual Congress delegates with an interest in medical education.

The 2017 forum focused on continuing professional development (CPD) for respiratory professionals, and was chaired by Gernot Rohde (Education Council Chair, 2014-2017) and Daiana Stolz (Education Council Chair, 2017-2020). The aim of the session was to give an overview on current CPD approaches and best practices and challenges. Perspectives were shared from three European countries, the UK, Spain and the Netherlands, all with very different healthcare systems. This editorial will summarise the key discussions.

\section{Why is CPD relevant for healthcare professionals?}

The medical field is constantly changing due to technological, societal and lifestyle developments (the ageing population, obesity, greater patient expectations, the internet, etc.), as well as environmental factors and the discovery of new information that can enhance clinical practice. At the same time, healthcare systems are stretched, with health professionals reporting that they have to do more with fewer resources [1,2]. The majority of doctors from the UK participating in the Royal College of Physicians' "NHS reality check: update 2018" report indicated that their situation had become worse in nearly all areas of care over the past year [2]. Therefore, the focus and importance placed on continuing education of healthcare workers and ensuring that health professionals have all the necessary medical and non-medical skills is becoming ever more important.

The European Union of Medical Specialists (UEMS) defines CPD as the educational means of updating, developing and enhancing how physicians apply the knowledge, skills and attitudes required in their working lives [3]. UEMS states that CPD additionally encompasses the many roles that physicians may perform that indirectly affect the quality of healthcare, such as teaching, research and management. CPD can entail: work-based learning, e.g. case discussions, journal clubs or peer review; professional activities, e.g. teaching or lecturing; formal education, e.g. attending the ERS Congress, attending courses or e-learning; and self-directed learning through reading scientific journals. Some of these activities might already be part of any healthcare professional's working life, without being claimed as CPD activities. 


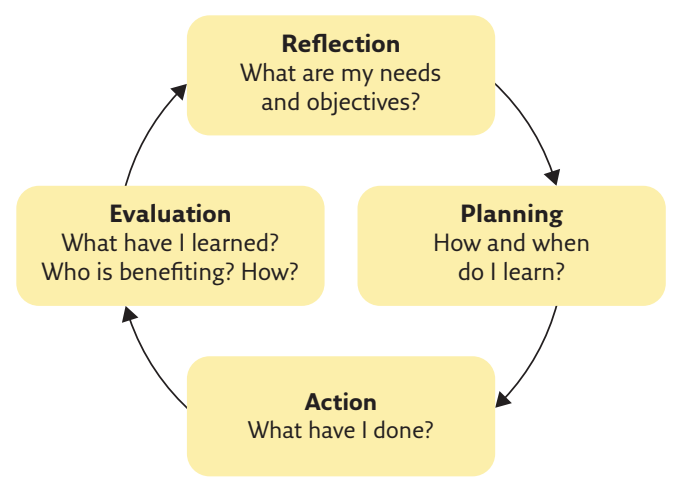

Figure 1 The CPD cycle.

To reach full potential, any educational activities should be part of quality improvement, and be aligned with clinical practice and individual needs. CPD management is best structured as a cycle (figure 1) [4]. Reflection on individual learning needs and learning objectives should form the first milestone, followed by planning on how and when to learn. Once the activity has been undertaken, the individual learning outcomes should be evaluated, posing the question of who is benefiting and how [5].

\section{What are the benefits?}

Staying fit to practice and up to date with recent developments is an integral part of the healthcare profession, if not an ethical and moral obligation. Actively engaging in learning activities can help to enhance the quality of healthcare. Research has shown that CPD activities can induce behavioural change and can thus improve physicians' performance. Examples of these improvements encompass prescribing, screening and adhering to guidelines [6]. Although somewhat inconsistent in terms of improved clinical practice outcomes, systematic reviews have identified an impact of CPD activities on knowledge, skills and attitudes.

\section{What are the possible challenges for CPD?}

In order for CPD activities to be beneficial, certain criteria need to be met. First and foremost, they need to be accountable and transparent. This means that any activities should be free of bias. Funding or sponsorship of CPD activities needs to be disclosed, particularly from medical device companies or the pharmaceutical industry. The role of industry sponsorship remains controversial, and is prohibited in some countries. This disclosure of interests must also be extended to teaching faculty and programme developers. Participants in CPD activities must be provided with all the information about industry involvement in order to be able to make an impartial judgement on the views and perspectives discussed during the activity.

The high costs of participating in educational activities are often a challenge and barrier to professional development. The following of professional development programmes, while compulsory in some countries, does not necessarily signify low-cost or free education for the professional. It has been reported that in some countries CPD activities were self-paid, and in addition professionals needed to take annual leave to attend these activities. This might challenge the feasibility of CPD, given that there is considerable variation across countries in terms of the resources available and personal financial investment.

\section{Country perspectives}

During the educational forum, the benefits and challenges around CPD were discussed from different national perspectives. As education is very context specific, differences in national programmes and the role of sponsorship does not come as a surprise. Systems vary widely across countries $[7,8]$. The information presented during the forum addressed national CPD systems for respiratory specialists as well as allied healthcare professionals.

\section{The UK perspective}

Martin Allen shared the UK perspective on CPD; he works in education at both undergraduate and postgraduate levels via extensive links with the British Thoracic Society and UK Department of Health. Prior to 2000, the UK had a selfregulated approach to CPD. Due to a number of high-profile cases involving patient safety, the General Medical Council started to make internal changes. In 2007 a white paper was presented to the government to develop a structured medicallegal framework. Nine councils were developed to ensure healthcare regulatory excellence; these councils are answerable to the government. The councils relevant for respiratory medicine professionals include: the General Medical Council (GMC); the Nursing and Midwifery Council; and the Health and Care Professionals Council. The other councils include: pharmacy, osteopathic, dental and optical. A council has a remit to ensure the professional behaviours in each of the healthcare areas. CPD is imbedded within these professional behaviours.

Today, doctors have to be registered with the GMC. Doctors must undergo revalidation, policed by annual appraisals. Employers are responsible and are held accountable for ensuring their workforce is up to date and practice to the appropriate standards. Each doctor has an annual appraisal, which builds 
into their 5-year revalidation schedule. Activities within the schedule include: an online diary, a minimum of 50 credits (hours) per year, quality improvement activities, significant events, and feedback received from peers and patients, as well reflection on compliments or complaints. Employers are responsible for providing feedback and signing off each appraisal. Other health professionals such as nurses, physiologists and physiotherapists have a similar process of legal registration. As with every structure there are known challenges to this framework; currently skills, outcomes and practice are not assessed.

\section{The Spanish perspective}

The Spanish continuing medical education (CME)/ CPD system was presented by Joaquim Gea Guiral, a professor of physiology in the UPF Department of Experimental and Health Sciences (CEXS) and the current dean of the university's Faculty of Health and Life Sciences. He is also board member of the European Board of Accreditation in Pneumology (EBAP), which accredits CME/CPD activities. The process in Spain is complex (figure 2). MD and PhD programmes depend on the Ministry of Education, which is linked to universities, while the medical specialisation programmes depend on the Ministry of Health, which is linked to hospitals and care centres. Each one of these institutions awards their corresponding certification. Moreover, medical practice also requires the approval of an official College of Physicians. Although there is an authority to guarantee the cohesion of the system (the Interterritorial Council of the Spanish National Health System (NHS)), the entire Health System (NHS) has been transferred to the Autonomous Communities.

In 1989, and despite such a complex scenario, the first steps towards the current CME and CPD system were taken with the creation of the Catalan Council for CME (CCCME), which was followed in 1998 by the formation of a study commission for a system that would be applied to the entire country (Spanish Commission of Continuing Education for

Ministry of Education

Ministry of Health

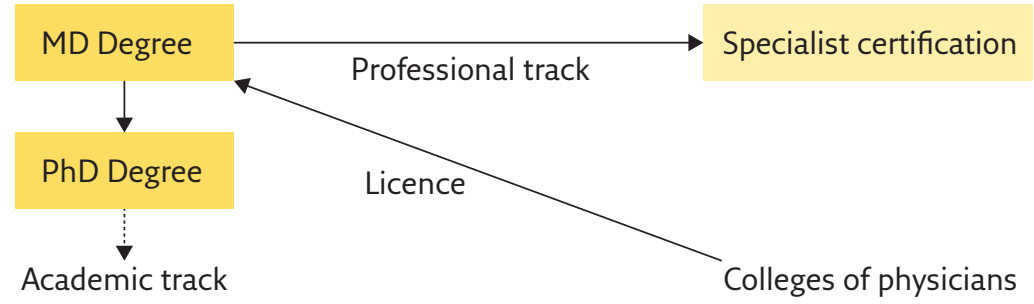

Figure 2 CPD in Spain. The Spanish NHS has been transferred to the Autonomous Communities, although the Ministry of Health and the Interterritorial Council of the Spanish NHS (CISNS) guarantees system cohesion and equity. The main CME credit providers are SACCME and the autonomic councils for CME/CPD (CCCME, Andalusian or CAFCPS, etc.).
Health). Finally, the Spanish Accreditation Council for CME (SACCME) was created in 2003.

Accreditation of CME/CPD activities is still not obligatory, although it can be useful for professional promotion in many of the Spanish NHS centres. Unfortunately, to date, there are no formal revalidation or recertification activities in Spain. The granting of credits may be at a national or a regional level, although universities, medical societies and medical colleges are working to harmonise the procedures. The Spanish providers of CME and CPD activities are mainly scientific/ medical societies (50\%), the NHS and its centres (20\%) and pharmaceutical companies (15\%), with the main funders being the latter (60\%), the NHS and associated centres (20\%) and scientific/ medical societies (10\%). Specifically, in the field of respiratory medicine, the Spanish Society of Pneumology and Thoracic Surgery (SEPAR) and the respiratory regional societies support the European Diploma in Adult Respiratory Medicine (EDARM) programme, with local training and preparation activities. The EDARM examination is modelled on the ERS HERMES adult respiratory medicine examination, which follows strict methodology for the development and maintenance of the examination [9].

\section{The Dutch perspective}

The Netherlands has set up a structured system to promote healthcare quality. Pascal L.M.L. Wielders is vice-president of a co-operative of medical specialists and works as specialist manager and supervisor. He explained that the law covering healthcare professions (law on Beroepen in de Individuele Gezondheidszorg meaning "professions in individual healthcare") intends to promote the quality of care. The law is also meant to protect patients or clients against improper or careless actions by individual healthcare providers. Doctors, pharmacists, physiotherapists, healthcare psychologists, psychotherapists, dentists, midwives and nurses are required to register. Only healthcare providers that are in the registry may carry a title protected by law and carry out the designated healthcare activities. The Health Authority supervises the training obligation that healthcare professionals have to maintain and update their professional knowledge. In addition, the Health Authority monitors the compliance of the healthcare worker to deliver good care and to take part in a quality assurance programme. Noncompliance is subject to disciplinary actions including: warnings, temporary suspension and striking from the register.

An additional framework has been set up to perform the tasks of the Health Authority. The General Medical Council (CGS) sets additional rules for registration and re-registration, in accordance with the scientific societies. The National 
Registration Committee (RGS) then checks whether individual applicants meet the criteria for (re-)registration. A separate committee for disputes and advice has also been installed.

In 2015, to ensure that each individual is competent to deliver good and safe care in their specialty, the rules were updated. Moving beyond independent performance, greater emphasis has been placed on the multidisciplinary team. Therefore, the scientific societies visit each hospital every 5 years to ensure that a team takes part in a quality assurance programme. The current re-registration criteria are: 1) experience (>16 h per week), 2) education (>200 CME per 5 years), 3) taking part in an accredited system in which individual performance is systematically evaluated ("individual development plan"), and 4) taking part in an accredited system in which team/department performance is systematically evaluated (by the scientific society). Non-adherence will lead to limited permission to carry out healthcare activities (e.g. for 1 year instead of 5 years), additional measures (e.g. training in certified centres) or, in the worst case, striking from the register and subsequent loss of licence.

The question remains, however, whether these measures will reach the predefined goals. The ultimate test would be to investigate the patient outcomes in countries with strict rules and compare these with outcomes in countries with less strict rules. In Pascal Wielders' experience at least $80 \%$ of complaints doctors receive are due to the underdevelopment of soft skills, such as communication, collaboration and professional behaviour, which is also supported by research findings $[10,11]$. Several hospitals in the Netherlands have now taken the initiative to improve these soft skills by developing programmes for young specialists to improve communication skills and leadership. Also a mentoring system, inter-professional coaching and support teams are being set up. The development of these additional skills may lead to improved quality of care and improved work satisfaction for professionals.

\section{Discussion}

A crucial point from the audience was made when the goal of CPD was discussed. The question regarding whether $C P D$ should target minimum standards, or whether it should strive for excellence arose. This discussion is ongoing in the literature; with discussions focusing on whether systems are designed to support professional development or to detect malpractice [12]. It is worth noting that regardless of what the ultimate goal might be, every healthcare profession should see active engagement in CPD as part of their lifelong learning and an ethical and professional obligation.
Throughout the discussion the resource barrier was hotly debated: in countries where the healthcare system is already under-resourced, professional development is not a high priority. Therefore, limited financial resources could really hinder participation in CPD activities, particularly if these are legally required. This lack of funding for CPD activities from healthcare institutions, together with underpayment of healthcare professionals, leads to a prominent role for pharmaceutical and medical device companies to either sponsor (and often act as the sole sponsor) live CME events, or sponsor more or less directly the participation of a healthcare professional in a CME event. Addressing all these opposing constraints into an acceptable CPD system is challenging and not yet solved. ERS recognises that cost is a barrier for certain members to participate in CME activities; therefore, ERS is currently looking into ways to make the activities more affordable for this group, while also reviewing the bursary procedure to support a greater number of early careers members in need.

\section{Future perspectives for CPD within the ERS}

ERS in is an independent medical organisation that collaboratively works with its members to drive standards and to offer high quality educational resources. ERS offers a wide variety of educational activities throughout the year and during the International Congress, which are driven by CPD best practices and principles. ERS requests CME accreditation for all activities from either the European Accreditation Council for CME or EBAP.

Discussions about best practices for CPD remain on the ERS agenda. ERS officers regularly attend international scientific and medical education meetings to discuss challenges and share learning. Feedback is welcomed at all times from local and national professionals that work in medical education.

The chairs concluded the session by presenting current and future directions for CPD within the ERS. ERS is dedicated to developing a framework to guide respiratory professionals CPD training. Currently eight working groups are developing content covering the eight most important respiratory disease areas, the outputs of this project will be presented at the 2018 ERS International Congress in Paris, France.

All in all, the goal to explore CPD systems across different European countries and to identify best practice in terms of how to deliver and develop CPD for respiratory professionals was met during this educational forum. Importantly, the forum paved the way for future discussions around how ERS can best use CPD in the future. 


\section{Interested in medical education?}

Join us at the 2018 Educational Forum "Ensuring impactful independent education" on Monday September 17, 2018, 15:00-16:00, at the ERS International Congress in Paris, France. The session will be facilitated by BBC Health Reporter, Vivienne Parry (MBE).

\section{Programme}

- Assessing the educational needs (individual, multidisciplinary team, country, profession/ specialty) (S. Aliberti)

- Importance of continuing medical professional development:

Patient perspective - patient outcomes (I. Saraiva)

Professionals' perspective - impact, behaviour change, ensuring standards, outcomes

(R. Stevenson)

Innovation (C. Jackson)

\section{Conflict of interest}

C. Sehlbach has nothing to disclose. A. Farr is an employee of the European Respiratory Society. M. Allen has nothing to disclose. J. Gea Guiral has nothing to disclose. P.L.M.L. Wielders has nothing to disclose. D. Stolz reports personal fees for consultancy from Roche AG, Novartis AG, Astra-Zeneca AG, GSK AG and Curetis AG; personal fees for lectures including service on speakers bureaus from Novartis AG; and grants/grant pending from Astra-Zeneca AG, Pan Gas AG, Weimann AG, Curetis AG and Boston-Scientific AG, all outside the submitted work. G. Rohde reports personal fees from Pfizer, Boehringer Ingelheim, Solvay, GSK, Essex Pharma, MSD, Grifols, Chiesi, Vertex, Roche and Novartis for lectures including service on speakers bureaus outside the submitted work and/or consultancy during advisory board meetings and personal fees from GSK for travel accommodation/meeting expenses outside the submitted work.

\section{References}

1. Wells J. Canadian Health System, Like UK, 'Stretched To Max Capacity'. www.acsh.org/news/2017/08/28/canadianhealth-system-uk-stretched-max-capacity-11753 Date last accessed: April 5, 2018. Date last updated: August 28, 2017.

2. Royal College of Physicians. NHS being 'pushed to its limit' according to reality check report. www.rcplondon.ac.uk/news/ nhs-being-pushed-its-limit-according-reality-check-report Date last accessed: April 5, 2018. Date last updated: March 12, 2018.

3. Union Européenne des Médecins Spécialistes. What is CPD? www.uems.eu/general/glossary Date last accessed: April 5, 2018.

4. Grant J. Measurement of learning outcomes in continuing professional development. J Contin Educ Health Prof 1999; 19: 214-221.

5. Brigley S, Young Y, Littlejohns P, et al. Continuing education for medical professionals: a reflective model. Postgraduate Med J 1997: 73: 23-26.

6. Cervero RM, Gaines JK. The impact of CME on physician performance and patient health outcomes: an updated synthesis of systematic reviews. J Contin Educ Health Prof 2015; 35: 131-138.

7. Peck C, McCall M, McLaren B, et al. Continuing medical education and continuing professional development: international comparisons. BMJ 2000; 320: 432-435.

8. Sehlbach C, Govaerts MJ, Mitchell S, et al. Doctors on the move: a European case study on the key characteristics of national recertification systems. BMJ Open 2018; 8: e019963.

9. Noël J-L. Getting ready to sit a HERMES examination: practical issues and tips. Breathe 2013; 9: 164-169.

10. Ha JF, Longnecker N. Doctor-patient communication: a review. Ochsner J 2010; 10: 38-43.

11. Jill T. Interprofessional education: a review of context, learning and the research agenda. Med Educ 2012; 46: 58-70

12. Archer J, Regan de Bere S, Nunn S, et al. 'No one has yet properly articulated what we are trying to achieve': a discourse analysis of interviews with revalidation policy leaders in the United Kingdom. Acad Med 2015: 90: 88-93. 